\title{
A Chronological Literature Review of Electric Vehicle Interactions with Power Distribution Systems
}

\author{
Andrés Arias-Londoño ${ }^{1, *}$, Oscar Danilo Montoya ${ }^{2,3}$ [D and Luis Fernando Grisales-Noreña ${ }^{1}$ \\ 1 Facultad de Ingeniería, Institución Universitaria Pascual Bravo, Calle. 73 \# 73a-226, \\ Medellín 050034,Colombia; luis.grisales@pascualbravo.edu.co \\ 2 Facultad de Ingeniería, Universidad Distrital Francisco José de Caldas, Carrera 7 No. 40B-53, \\ Bogotá D.C 11021, Colombia; o.d.montoyagiraldo@ieee.org or omontoya@utb.edu.co \\ 3 Laboratorio Inteligente de Energía, Universidad Tecnológica de Bolívar, km 1 vía Turbaco, \\ Cartagena 131001, Colombia \\ * Correspondence: andres.arias366@pascualbravo.edu.co
}

Received: 31 March 2020; Accepted: 2 June 2020; Published: 11 June 2020

check for updates

\begin{abstract}
In the last decade, the deployment of electric vehicles (EVs) has been largely promoted. This development has increased challenges in the power systems in the context of planning and operation due to the massive amount of recharge needed for EVs. Furthermore, EVs may also offer new opportunities and can be used to support the grid to provide auxiliary services. In this regard, and considering the research around EVs and power grids, this paper presents a chronological background review of EVs and their interactions with power systems, particularly electric distribution networks, considering publications from the IEEE Xplore database. The review is extended from 1973 to 2019 and is developed via systematic classification using key categories that describe the types of interactions between EVs and power grids. These interactions are in the framework of the power quality, study of scenarios, electricity markets, demand response, demand management, power system stability, Vehicle-to-Grid (V2G) concept, and optimal location of battery swap and charging stations.
\end{abstract}

Keywords: battery swap station; charging station; demand management; demand response; electric vehicle; electricity markets; power quality; Vehicle-to-Grid

\section{Introduction}

Over the last few years, electric transport has been largely promoted by governments as an effort to reduce dependence on fossil fuels and air pollution from vehicles propelled by internal combustion engines (ICEs). Electric vehicles (EVs) have become an important component in this subject due to the advantages presented compared to ICE vehicles, i.e., reduction of noise and notable decrease in greenhouse gases release. Furthermore, a massive introduction of EVs in the power distribution networks leads to adverse effects in terms of the following:

- voltage drops,

- non-desired load peaks,

- increment in energy losses,

- overload on grid components,

- load factor reduction,

- reliability indices deterioration, and

- $\quad$ power quality issues. 
A large quantity of research around the interaction of EVs with power distribution systems is found in specialized literature. Particularly, in the IEEE Xplore database (one of the most important worldwide scientific research databases), this subject has been strongly addressed for a bit more than ten years.

Despite the extensive knowledge published in this database, few literature reviews can be found in this regard. Some of the reviews are reported in [1,2]. In [1], recent literature focusing on distribution system services provided by EVs is presented based on three categories: active power support, reactive power support, and renewable energy source integration support. Weaknesses in the control strategies are identified to encourage the exploration of new areas aligned with the current requirements of smart grids. On the other side, Dubay and Santoso in [2] perform a detailed review to evaluate and mitigate the impacts of charging EVs on residential distribution systems. Other relevant reviews are shown by [3,4]. In [3], certain operating features such as voltage stability, peak load, power quality, and transformer performance are considered as key classifiers; conversely, Jia in [4] introduces a more general classification focused on objective functions, optimization methods, and market design. Furthermore, works such as [5] develop a comprehensive review using a systematic classification considering a wide approach to the EV-power grid interaction.

Compared with the literature reviews mentioned above, the primary contributions of this paper are listed below:

- provide a chronological literature review through the end of 2019 of research on the interaction between EVs and power distribution systems, found in IEEE Xplore database;

- perform a detailed and systematic classification of the papers that address EVs and distribution networks, considering relevant categories, e.g., power quality, demand management, power system stability, Vehicle-to-Grid services, and demand response, among others;

- identify the topics that need further exploration, mindful of the upcoming increase of EVs recharging on power grids.

The present article is an updated and improved version of the conference paper in [5]. The rest of the article is divided in the following sections: A general overview of the time window under research for the development of this review is presented in Section 2. Sections 3 and 4 present a time-sequential revision subperiod, for the periods 1973-2015 and 2016-2019, respectively, considering a debugged list of papers from the IEEE Xplore database. The review is developed by using key categories in regard to the type of interactions between EVs and power distribution systems. Section 5 presents some observations and comparisons between the mentioned periods, followed by Section 6 which provides conclusions of the work and avenues of research. Finally, some final reflections are included in Section 7.

\section{General Overview}

The literature review relevant to the interaction of EVs and power distribution networks is based on an exhaustive search of the works published in the IEEE Xplore database from 1973 to 2019. Firstly, the term "electric vehicle" was used as a key parameter in the database browser, obtaining around 64,400 papers associated with this criterion. Secondly, it was decided whether the paper was assigned to the study according to its content, since several works are not related to EV and power grid interactions, despite the key term filter "electric vehicle" in the browser. Those papers that were not within the theme of this literature review were discarded since their subjects were generally associated with other topics in terms of vehicle operation, i.e., propulsion system, architectures, brake recuperation, power train control, velocity profile optimization, and motion planning, among others. Subsequently, the remaining papers were listed in a debugged database, according to a specific subject in relation to EVs and power grids, as shown in Table 1. The complete list of papers investigated to develop this review can be found in [6]. 
Table 1. Ranking by number of publications.

\begin{tabular}{clc}
\hline Identification & Topic & Number of Publications \\
\hline ID1 & Power quality & 104 \\
ID2 & Scenarios study & 498 \\
ID3 & Electricity markets & 125 \\
ID4 & Demand response & 83 \\
ID5 & Demand management & 514 \\
ID6 & Power system stability & 164 \\
ID7 & Vehicle-to-Grid (V2G) & 343 \\
ID8 & BSS and/or EVCSs & 239 \\
\hline & Total & $\mathbf{2 0 7 0}$ \\
\hline
\end{tabular}

According to Table 1, the first column identifies the work category. The works identified as ID1 assess the reliability and harmonics level, caused by the recharge of the EVs in the distribution network, providing results in terms of indices such as total harmonic distortion (THD) and current and voltage signal spectra. This category is relevant since the internal components of the EV are considered as harmonic signal sources. ID2 identifies the evaluation of network load factor, energy loss lines, and transformer overload, among other aspects, under different insertion levels of EVs. Other aspects addressed in this category are the stochastic analysis, usage politics, and EV growth trends in the automotive industry. The works belonging to ID3 consider studies framed within the EV participation in electricity markets, energy price, and cost-to-benefit ratio. The publications identified as ID4 correspond to those works in which the demand response provides an opportunity for EV owners to play a significant role in the operation of the electric grid, by reducing or shifting their EV recharge during peak periods in response to financial incentives. In ID5, the works include mathematical programming, focused on minimizing the operation and investment costs and/or maximizing the quantity of EVs that can be plugged into the network, considering operative constraints (load factor, voltage limits, and maximum current flows) and EV owners' driving patterns. ID6 is a category for the studies in which the EVs provide signals to support power system stability, including ancillary services and voltage, frequency, and small signal stability. The Vehicle-to-Grid (V2G) concept, and the interaction of EVs with distributed generation sources and power storage systems, is developed in publications with ID7. Last but not least, category ID8 presents the works that address the EVCSs (Electric Vehicle Charging Stations) planning and BSS (Battery Swap Stations) in distribution systems, supported by one or some of the following aspects: path planning, transportation network, queuing analysis, traffic flows, routing, and charging station configuration.

In accordance with Figure 1, the impact of EVs on distribution networks was seldom studied during the 1970s, with only one publication in the IEEE Xplore database reported in the year 1973. In the following decade, the scope was not notably changed, with only three publications. Furthermore, the research pipelines were expanded to study the quality of power (ID1). Later, between 1990 and 2006, another category (ID5) showed up in the list mentioned before, which signifies a starting point for mathematical modeling and optimization, focused on the timely demand management of consumers and EVs. In general, between 1973 and 2006, the efforts around this discipline involved almost twenty publications considering power quality, scenario studies, and demand management. 


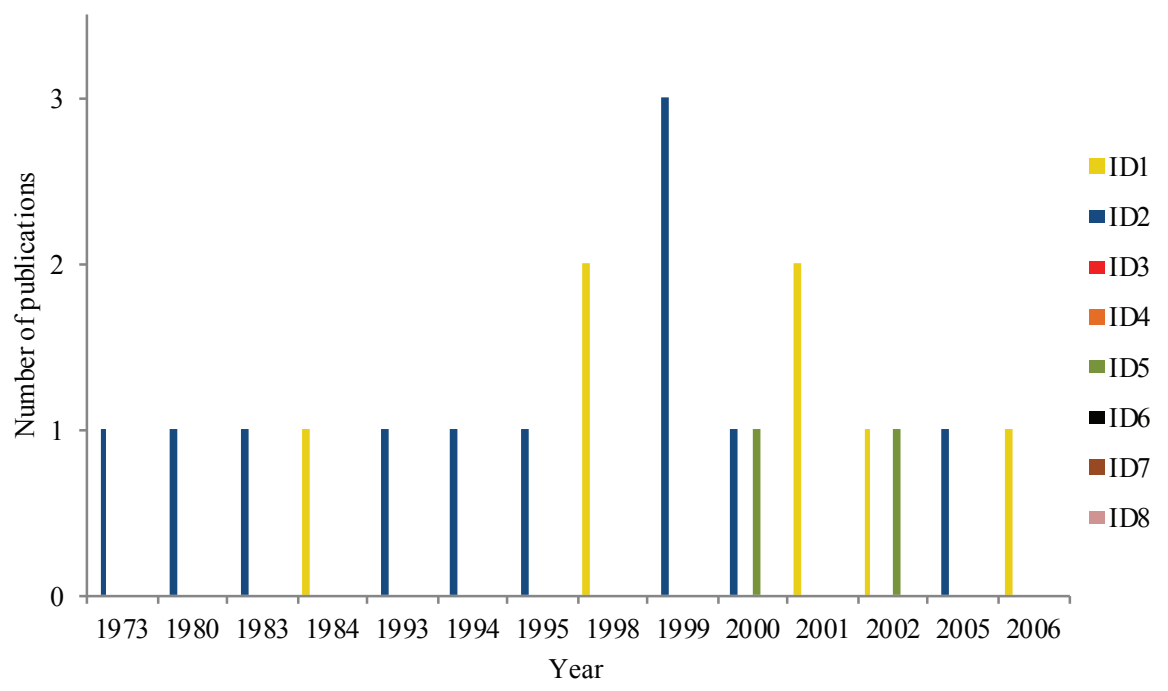

Figure 1. Research trends of EVs and distribution networks, 1973-2006.

Figure 2 provides details on the publications from 2007 to 2019. In 2007, research trends showed the same behavior as in Figure 1; however, in 2008 the range of study choices expanded to EVs participating in electricity markets, power systems stability, and grid support under the V2G concept. In 2009 another trend arose, featured by the works framed within the role played by EVs in the context of demand response. The year 2010 represents a point in which there was a large increase in the number of publications on EVs and their interactions with power networks. In the same year, the optimal locations of EV charging stations and battery swap stations were introduced in the list under study.

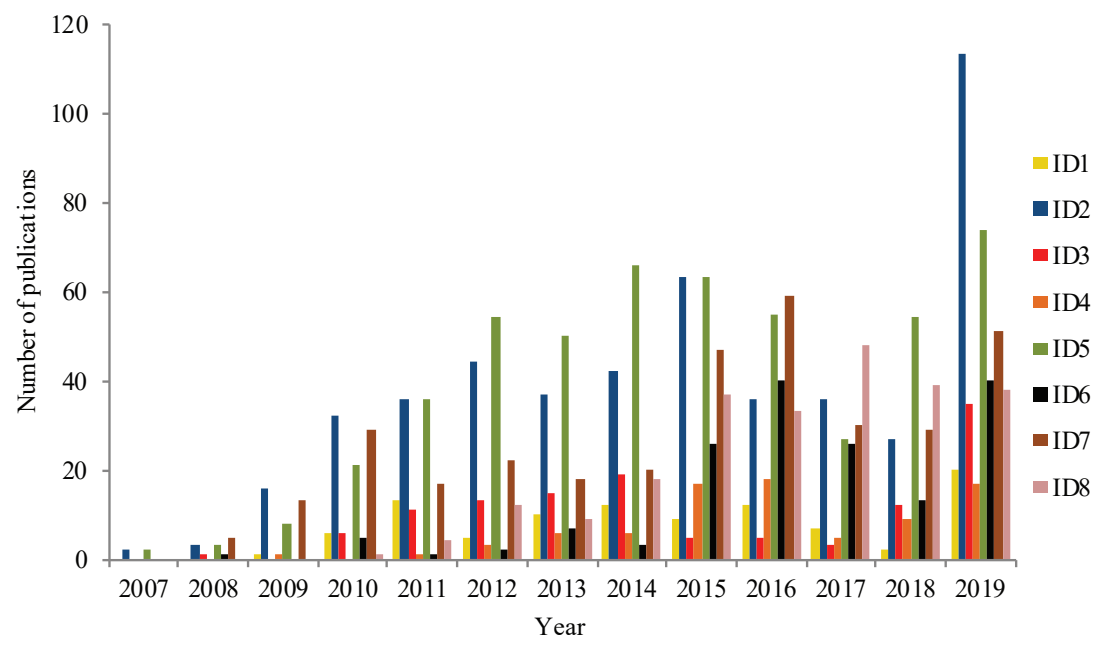

Figure 2. Research trends of EVs and distribution networks, 2007-2019.

According to Figure 3, the period of time 2010-2019 covers the largest number of publications, as the need for network operators and the academic community to manage and confront the increase of EVs plugged into the distribution network increased. In the time-lapse considered for the development of this literature review (1973-2019), the number of works included up to 2070 publications, encompassing journals and conferences. As presented in Table 1, the current state of research was classified in compliance with the research stream and number of publications. This does not imply a low importance for the category with the lowest number of publications.

In the following sections a survey of the main works is addressed, taking into account the categories mentioned above and the 1973-2019 period divided into key subperiods. Since the database 
is extensive in addressing the total of papers in the review, the choice of the papers addressed throughout the development of this review corresponded to a rigorous examination of each paper listed in the filtered database posted in [6]. In the examination, the contributions and the novelties applied to solve the problem of a certain topic/category were considered. From our point of view, the article was not cited if its proposal to solve a certain problem was framed within conventional strategies without any novelty.

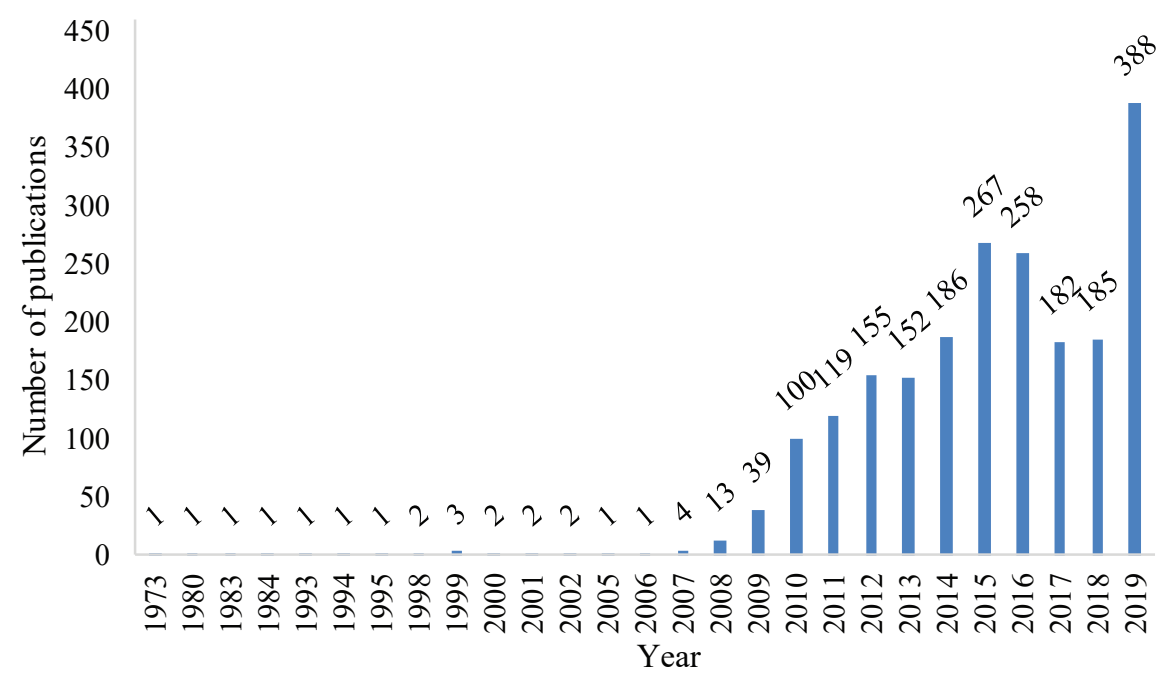

Figure 3. Growth of research from 1973 to 2019.

\section{Chronological Review: Part I}

This section of the chronological review is focused on the first half of the total papers listed in [6], i.e., 1055 papers for the period 1973-2015. In Figure 4, the participation percentage of the categories is depicted over this first set of works, with a major presence of works focused on demand management and study of scenarios, followed by the V2G concept with a $16 \%$ of participation.

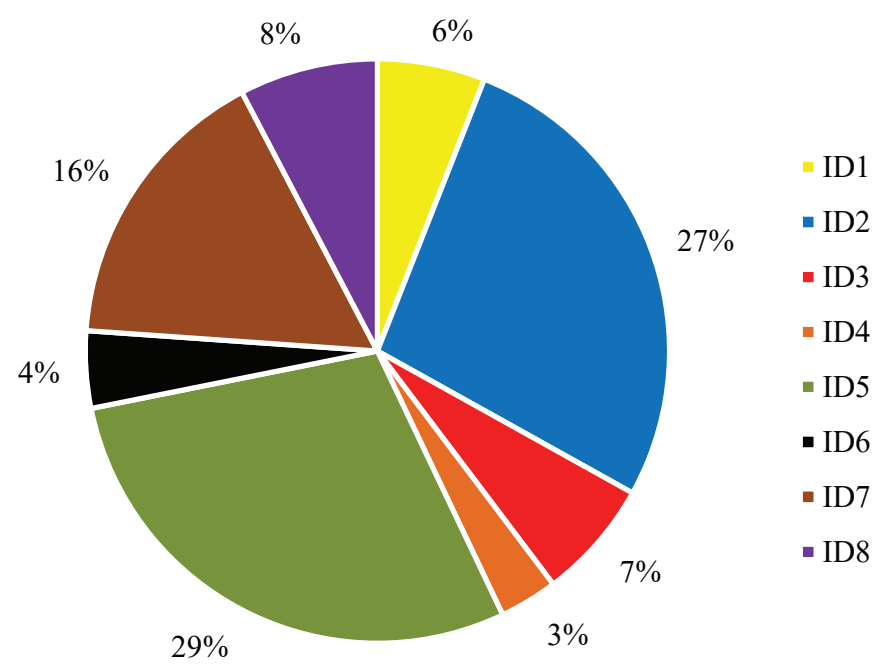

Figure 4. Participation percentage of categories: first half.

\subsection{Subperiod 1973 to 1999}

As earlier mentioned, the theme of EVs and electric grids interacting started to be researched in the 1970s, according to the IEEE Xplore database. Specifically, in 1973, in [7] a start point of this 
research was presented, expressing the relevance to conduct a study around the imminent deployment of EVs in the coming years and their impact on generation plants and distribution systems. However, it was not until 1980 [8] that electric companies become more receptive to topics related to the recharge of EVs, stimulating recharge at night time to increase the load factor of the system, and decrease the cost per kWh. Hence, supported in mathematical definitions and technical arguments, [9] presents a study about improving the load factor, opening the possibility for demand management strategies to focus on cushioning the collateral effects of EVs. Not only was load factor improvement one of the study topics in the 1980s, particularly in 1984 the impact of power quality started to be researched, due to the non-linear nature of battery chargers of EVs [10]. These devices can distort the voltage signal and generate harmonic currents, which create problems for power systems, e.g., increase in neutral current, hot spots in transformers, and inaccuracy on measure instruments. To solve these problems, in [10] a current smoothing within the EV charger circuit is proposed.

Since the 1990s, the study of scenarios of EVs in electric networks had become more popular than the power quality studies. This was due to the growing interest to determine strategies allowing EVs to be recharged at hours of low conventional demand and, thus, to flatten the load curve. In this context, Rahman and Shrestha in [11] stated that not only does having sufficient capacity of generation during valley hours need to be considered, and to provide energy to EVs without adverse effects on the electric grid, but it is also necessary to study the strength of distribution systems in order to support these load additions. Since a large quantity of EVs should be recharged during the low-demand period, a considerable EV load can generate non-desirable demand peaks at the beginning of this period. Thus, the need arises to develop fast-charging batteries to recharge some EVs at the end of the valley period and make the demand curve more uniform.

In [12], the necessary elements are successfully established to boost the EV market, among them, the development of batteries with enhanced characteristics and the willingness of distribution companies to improve their electric infrastructure to ensure reliable and timely delivery of energy to a great quantity of EVs. By the year 1995, according to [13], the EV technology remained in prototype status in terms of production and development of batteries; therefore, the number of EVs on the streets for the next twenty years aimed to speculate data. This represented an obstacle to define the load model of the EVs. Three years later, in 1998, the efforts were concentrated again on the problems of power quality, where [14] presented a statistical method to determine the maximum penetration threshold of EVs in a distribution system, so that the THD index did not exceed over 5\%. The same year, with the intention to model appropriately the EV load in the system, Ref. [15] shows the modeling of EV chargers from a procedure in which a Montecarlo simulation was used, which obtained the THD in terms of an expected value and a standard deviation. Nevertheless, in contrast with the aspects mentioned in [11], from the point of view of the distribution company, a fast charge is not desired because of the resulting big demand peaks. Despite the motivation for this kind of recharge in low-demand periods, its usage is suggested in emergency cases. Under these supposed disadvantages, quick chargers receive a lot of interest when the likely effect of this type of charger in the distribution system is known [16]. In that work, assessment of the size and influence of EV charging harmonics versus the penetration level is presented. Other works such as [17] discuss the behavior of the demand curves, considering random aspects like the initial time of recharge of EV and the state of charge (SOC). At the end of this decade, the report presented in [18] explains the development of EVs in the last thirty years, the effect at the environmental level, and electricity generation, confirming the terms established in [7] when the scale is tipped again to improve the performance of these vehicles.

\subsection{Subperiod 2000 to 2009}

At the beginning of the 21st century, the field extended to the role played by EVs as distributed resources to supply, partially or totally, the domestic demand in periods of time where the energy price is relatively high [19]. Under this scheme, some benefits include reduction of energy cost paid by the customer, mitigation of stress perceived by the transformers and distribution lines, privileges related 
with tax decrease and ease to build recharge infrastructures at their homes, among others. Taking into account the aspects above, it is important to point out the work done by Ceraolo and Pede in [20], where the distance traveled by an EV is estimated with the remaining SOC and the ability of the battery to provide energetic capacity as a function of the discharge rate. In 2002, power quality issues caused by EV recharge were addressed again, showing a quadratic relation between the transformer useful life and current THD index of the battery charger, establishing a limit between $25 \%$ and $30 \%$ for the THD to provide a reasonable life expectancy for the transformer [21]. Taking up the usage of EVs as distributed resources, it is mentioned in [22] other advantages in this framework, such as mobile AC power, backup energy for homes and offices, stability ancillary services, spinning reserves, and regulation. Due to the incrase in battery activities, not only in EV mobility but also in the area of ancillary services, it is necessary to take into account the economic viability of this framework because the useful life of the battery is reduced when the charge/discharge rate is increased. In 2006 and as a consequence of doing deeper research about the potential of EVs in electric networks, Breucker et al in [23] highlight the services presented by EVs fleets:

- elimination of harmonics, as the non-linear elements of the battery chargers act as active filters,

- power factor improvement by injecting reactive power and peak shaving,

- primary and secondary control for the power balance between the generation and the demand,

- frequency regulation in low-stability grids, inclusive with a lower quantity of EVs, and

- Ancillary generation for outages and construction projects.

During the year 2007, the focus was on conventional topics (scenario studies and demand management) without great contributions. The year 2008 represents a start point for the participation of EVs in power system stability and electricity markets. A clear example is the work published in [24] where the small signal stability of a power system with EVs is analyzed, which can act as constant current or impedance load. The results show that, when the EVs are charged in constant current mode, the electric network is prone to instability. Hence, in constant impedance mode, high penetration levels of EVs can be reached before the instability point. Related with electric markets, in the same year, [25] worked with the effect of EVs on the locational marginal price (LMP). This framework of wholesale electricity prices is determined from the incremental cost of re-dispatching a system to supply an additional demand unit in a specific location, subject to generation and transmission constraints. The EVs are loads that can be recharged at different geographic points and can influence greatly on LMP. Apparently it was not until 2008 that the term V2G (Vehicle-to-Grid) was made official to characterize the ancillary services of EVs to the grid, although in previous years this topic had already been addressed. In this context, some works such as [26], study the requirements for the V2G concept. The existing information flow between the network operator and the EV encompasses the following: the ID of EV, the preferences and parking status of EV, battery storage capacity, SOC, and the power flow from the battery to grid. However, the most important aspects consider the communication range of the system and security in the information transmission, besides the fulfillment of IEEE Standard 1547 where the minimum requirements are established to introduce energy to electric grids [27]. Other publications like [28] consider the relevance of V2G concept for electricity generation balance in environments highly penetrated by distributed generation, as in the Denmark case where around 20\% of its energetic capacity comes from wind generation. Conversely, a study done by [29] determined that the viability of increasing EVs in the Azores islands was related with the energy usage coming from renewable sources for recharging EVs.

Efforts focused on demand management, scenario studies, and the V2G concept increased in 2009. Mathematical modeling appears as a new alternative to study the effects of EVs in distribution systems. The topics related with demand response and power quality arise again, although in low proportions. With respect to the V2G concept, the study done in [30] proposed a mathematical programming model for optimal dispatch of generation units, which include the small thermal units and the energy stored in EVs, considering technical, spatial, and temporary constraints. Particle Swarm 
Optimisation, or PSO, was used to solve the problem, obtaining an increase in benefits and reliability in the distribution system. It is necessary to point out, through the stability stream, the work performed by El Chehaly et al. in [31], which proposed a Short-Term Voltage Stability Index (SVSI) for wind generation with ancillary services provided by EVs. This index is based on the difference between pre-fault voltage and the minimum voltage reached at fault status; in this manner, with a high number of EVs present, SVSI can be reduced, and the voltage profile is improved. Similar to [30], in [32] a mathematical model was designed in order to maximize the number of EVs plugged into distribution systems, subject to voltage limits and battery energetic requirements. This same philosophy was applied in [33] where minimization of the losses in the system is sought through coordinated charging of EVs. In each iteration of the optimization problem, a conventional load flow is executed to determine the actual network status. A necessary work to highlight for its connection between electric grids and the distribution network gas is the one presented in [34], where losses of both grids are minimized through the transformer's tap control and the compressor's output pressure, in order to cushion the impact of EV load.

\subsection{Subperiod 2010 to 2011}

In 2010, one of the most studied topics was the V2G concept, whose proposal consists of providing power at peak demand hours and absorbing power at minimum demand hours, taking advantage of storing energy of EVs. This is established by [35], where the need to synchronize charging and discharging of EVs with the smart grid is presented in order to avoid overloading in the distribution system. A specific study of this topic is done in [36], where a known network is considered with several scenarios of EVs inclusion, from $10 \%$ to $30 \%$. In [37], the V2G interaction is used to decrease the percentage of distribution transformers losses. There, the authors make the analysis by using a Time-Coordinated Optimized Power Flow (TCOPF), where EVs are considered as distributed generation, making an optimal dispatch of energy according to their requirements in an interval of time. Efficiency improvements of the system are achieved because the EVs consume power from the grid while the demand is low, leveling the valley of the demand profile and reducing the peaks in hours of maximum demand. Under these circumstances, events of charging/discharging the EV battery when connected to the power grid greatly influence battery aging. In this sense, P. Venet et al. presents in [38] a data-driven approach to analyze real-world usage of batteries in EVs, considering different road conditions (urban, extra-urban, and highway), which can result in a useful tool to characterize EV architectures and estimate their functionalities with the V2G concept.

Other contributions, those shown in [39], explore the economic incentives that EVs users can receive by contributing to soften the load profile curve. Incentives are made by offering refunds to EVs buyers, taking as reference the project carried out in California where each customer with photovoltaic energy capacity installed is eligible to obtain a discount of 2.5 USD/Wp. In [40], the inclusion of plug-in hybrid electric vehicles (PHEVs) in distribution systems is considered as a factor to recuperate the voltage stability; therefore, a method based on neural networks to determine a voltage stability index given a specific condition is shown. Additionally, in the same year some studies were developed with stochastic processes [41], demonstrating the importance of an intelligent strategy to charge and discharge EVs. Following this research stream, in [42] EVs are studied in different statuses-the first status presents a car in motion, the second status suggests a car parked in an industrial area, and the third status supposes a car parked in a residential zone. The status of each vehicle at a given time is assigned according to a Montecarlo simulation. Two levels of EV insertion are considered: 25\% and $50 \%$.

The next year, in 2011, some works like [43] developed a model for the market and infrastructure of EV recharge stations. As the year before, V2G interaction gained prominence, with the study of frequency control on grids with a high degree of generation by renewable energy sources [44]. The works in $[45,46]$ present the possibility to use EVs and PHEVs as dynamic containers of electric power, which can be set up at any time; while in [47], an optimization algorithm combined with 
Voronoi polygons is implemented, which locates equitably recharge stations, obtaining load balances according to the distribution of vehicles and the network topology. In [48], Falahati et al. evaluate reliability indices in an existing system with different EV insertion levels, concluding in particular that the test system used is not ready enough to supply the necessary demand for these elements in the system. Therefore, as formerly mentioned, the relevance of coordinating EVs and the electric network is confirmed. The impact of over-sizing the capacity of the network is analyzed in [49], where a general methodology using structural data for this proposal is presented.

Several works treat the interaction between EVs and power grids from the economic and technical perspectives, posing optimal charge and discharge schedules for the EVs; however, there is an issue on behalf of the EV owner related to the acceptance level of this person to use the network to charge the vehicle battery when permitted, and deliver the energy stored on it when needed. This topic is studied in [50], where the synchronization is not with the EV and its charge and discharge schedules, but with the owners of these vehicles and their needs because these EVs owners can dispose of the energy from the network at any time; therefore, regulations have to be presented to restrict the schedules and load capacity of each vehicle.

\subsection{Subperiod 2012 to 2015}

A large variety of studies done in 2012 used advanced optimization techniques, as the case of [51] where dynamic programming is used in order to determine the minimum current needed to achieve a desired SOC in the batteries, reducing the grid losses and the chance of wires overloading. In [52], in order to avoid an electric system saturation, a tariff plan is proposed to decrease the quantity of EVs running daily. This is done based on the day-ahead market, using a dynamic tariff that varies according to the energetic scheduling of the day. In [53], the concept of battery swap station is used; this is an idea that achieves to increase the dynamism around vehicular traffic. This scheme does not affect daily tasks of users when the batteries removed are charged at valley hours.

As it advances, some of the topics slightly missed were taken up, as the case of the power quality due to harmonic distortions, which is studied again in [54,55], demonstrating that the most important harmonics (3rd and 5 th harmonics) injected into the grid cancel each other out when a large quantity of EVs are connected in the same grid. Later, in [56], the chance to use the EVs as a backup source at homes is studied, incorporating the V2H (Vehicle-to-Home) scheme to supply the individual demand during interruptions of power delivery during short periods.

In 2014, additional works represent the EVs smart charge, used to flatten the load curve [57] with diverse methods and test systems. In [58], the technical impact over the distribution networks is not the unique topic of interest to study, but also the environmental impact carried out by the EVs usage, through $\mathrm{CO}_{2}$ reduction, which is demonstrated in the results obtained. In [59], an optimization work is done where the benefits of battery swap stations and the recharge stations are compared. It is demonstrated that the battery swap system is more suitable to apply in public transportation because the times for recharging batteries can be larger than the times taken to replace a depleted battery for a fully charged one.

Some works in 2015, such as [60], demonstrate efforts in the improvement of the distribution system under the V2H and V2G concepts, considering non-served energy indices. Thereby, in two test cases an improvement is achieved; the first case is composed of a centralized technology for EV recharge (V2G mode), and the second case is formed by disperse EV charging stations (V2H mode). Within this framework, in the V2G paradigm the reliability of the EV battery must be guaranteed, and proper state of health techniques should be applied accordingly, as presented by P. Venet et al. in [61]. In the context of energy markets, prominent works were published in 2015. As mentioned in [62], the revenues are the decisive factor in terms of integrating EVs into the energy market. In the United States and some European countries, EVs participate in several business cases framed in primary, secondary, and tertiary reserve power, peak load reduction, and day-ahead energy markets. A more detailed focus is depicted by [63], where a centralized real-time EV charging management 
from an EV aggregator that participates in the energy and regulation markets is developed. The EV aggregator optimizes the market bidding strategy using a two-stage stochastic optimization model, which produces optimal first-stage decisions for submission in the day-ahead market and second-stage scenario-dependent decisions for submission in the real-time market. The model can account for all uncertain day-ahead and real-time conditions as well as energy deviations between day-ahead and real-time energy markets. The storage technology implemented in EVs offers an attractive alternative for EVs to support the Short-Term Operating Reserve (STOR). According to [64], storage can help manage imbalances between electric power generation and consumption that could result in undesirable impacts across the entire network. Among the reasons for which this technology is a good option for STOR are

- storage has superior part-load efficiency,

- efficient storage can use twice its rated capacity (i.e., it can stop discharging and start charging at the same time), and

- storage output can be varied very rapidly (e.g., output can change from $0 \%$ to $100 \%$ and from $100 \%$ to $0 \%$ ).

From the EV perspective, STOR implementation is highly dependent on several critical factors, among them are state of charge, connection availability at times of grid requirement, fast response, and capability of providing twice the rated capacity.

Ancillary services, such as active power control and voltage support, are expected to be provided by EVs [65]. The first service is associated with the balance between production and demand to guarantee a secure operation of the electric grid at a constant frequency. Voltage support has to be performed locally because voltage fluctuations in power systems are usually due to the variation of reactive power demand and its transmission along the power lines. Since reactive power cannot be transmitted over long distances, voltage control has to be carried out by using special devices dispersed throughout the system to produce the necessary reactive power to match demand and keep the voltage within appropriate limits. According to the tasks developed by frequency and voltage control, EVs must comply with the following four criteria: supply duration, directional shifts, response rate, and service duty. Supply duration refers to the time over which the device, in this case the EV, has to be available to provide the ancillary service. Directional shifts are associated with sudden changes in charge and discharge of the batteries, which is suitable for short and volatile services. Long directional shifts are not convenient for EV batteries due to the degradation effects on the assets. Response rate is the time within which the resource providing the ancillary service needs to initiate service, which can be from less than one minute up to one hour. Service duty refers to the intermittent or continuous nature of consumption of ancillary services. The first one enables the EV to be charged while it is not providing the service.

In the framework of frequency control, Izadkhast and Garcia in [66] propose a new model to assign a participation factor to each EV, which facilitates the incorporation of several EV fleet characteristics, i.e., minimum desired state of charge, drive train power limitations, and charging modes (constant current and constant voltage). Participation factor defines the EV's availability to provide the primary frequency control. A wider range of responsive devices, e.g., inverter-based photovoltaic systems, EVs, and domestic controllable loads, are considered in [67] for frequency and voltage control based on power sensitivity analysis. These devices are classified according to the controllability degree. Once a voltage or frequency violation is detected in the system, the most effective buses are identified and receive the most effective control signals to perform appropriate changes in their reactive or active powers. In [68], a control technique is proposed to mitigate the charging current ripple when the current shifts the reference. A different approach is presented by Poornazaryon et al. in [69], where a method for primary and secondary frequency control is proposed based on artificial neural networks to train and validate the advanced droop control. Other works are framed within the computational decrease by using modified constraints in the mathematical model, 
such as the approach performed in [70]. The MTZ (Miller, Tucker, and Zemlin) formulation is used as a tool to avoid sub-tours in the vehicle routing problem, in order to obtain BSS locations and improve algorithm performance.

\section{Chronological Review: Part II}

The second half of works correspond to the papers listed in [6] in the range of time 2016-2019, with a total of 1015 papers. According to Figure 5, demand management and study of scenarios were the most prominent and had the same percentage, followed by the V2G concept category. In comparison with proportions shown in Figure 4, the positions for the first four categories remain equal, and a variation in the last four positions can be noted. Particularly, the categories of electricity markets and power quality held one and two positions respectively. On the other hand, a rise in two positions and one position, respectively, for the categories of power system stability and demand response were observed.

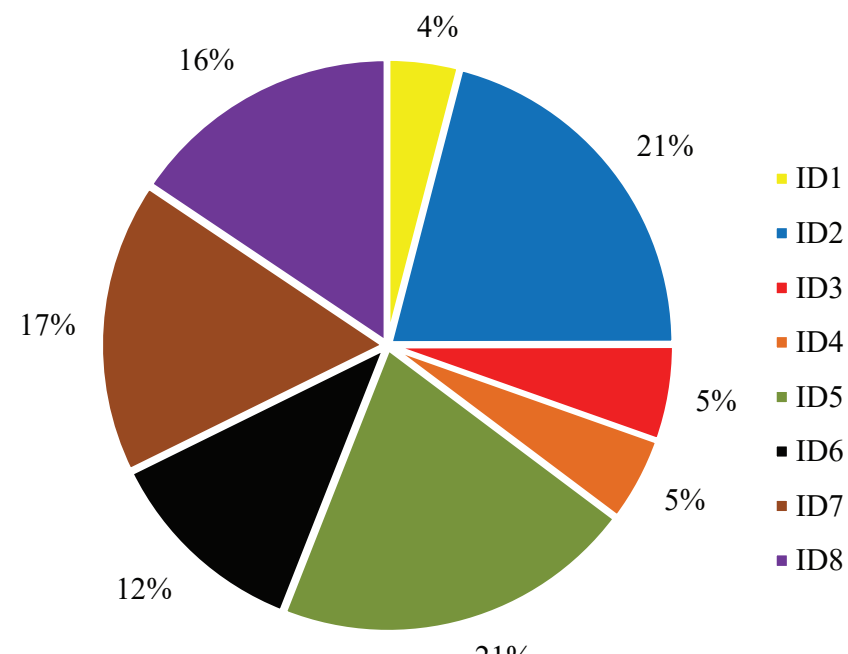

Figure 5. Participation percentage of categories: second half.

\subsection{Subperiod 2016}

Returning to EVs and their interaction with electricity markets via the aggregator concept, in 2016 Zhang and Kezunovic in [71] present contributions in the analytical estimation of aggregated EV charging/discharging power capacity, taking into account EV stochastic mobility and driver behavior, to improve the ramp rate of conventional generators through cooperation, and to participate in the ramp market on the system's reliability and flexibility as well as on EVs themselves. EV fleets can be aggregated in a mobile energy storage, which has the potential to compensate the un-contracted power if the contracts between the market players are breached. In this way, [72] performs an optimal strategy for both energy and reserve markets considering trade off and effect on EV battery degradation, in order to assess the expected profit that an aggregator can collect by participating in the energy and regulation market.

Continuing with the research approaches in 2016, some contributions are addressed in the context of demand response. This concept can avoid building new large-scale power generation and transmission infrastructures by improving the electric utility load factor. In [73], a demand response strategy is proposed for shaping a load profile to tackle the problem of overloading in distribution transformer when the EVs are used along with other loads. Overloading is first analyzed, and then the demand response is used to mitigate it once the total load exceeds the rated power of the distribution transformer. A more structured work is implemented in [74] from the mathematical model perspective, representing the total load at a charging station, considering a queuing model 
followed by a neural network. The queuing model considers arrival of EVs as a non-homogeneous Poisson process, and the service time is represented by using detailed characteristics of the battery. The charging station load (which is a function of the number and type of EVs charging at station, total charging current, arrival rate, and time) is integrated within a distribution operations framework to determine the optimal operation and smart charging schedules. Some works classified in the demand response can also be enrolled in the demand management approach. This situation is presented in [75], with a proposal to achieve a grid-friendly charging load profile based on the transactive control paradigm. In this way, EV owners can participate in real-time pricing electricity markets to reduce their charging costs. Similar efforts are presented in [76], developing a model for optimal behavior of EV parking lots in the energy and reserve markets, within the framework of price-based and incentive-based demand response programs. Concluding with this year, a practical case study is carried out in [77], evaluating the impact of EV uptake on Britain's power distribution networks by monitoring 200 customers during 1.5 years. At current projections for EV insertion, upgrading low-voltage infrastructure will cost consumers approximately USD 3 billion by 2050. This cost can be largely avoided if the demand-side response is deployed to shift EV charging away from times of peak demand.

\subsection{Subperiod 2017}

As depicted in Figure 3, the research around EVs and their interaction with distribution systems from different perspectives reduced by approximately $29 \%$ in 2017, in contrast with 2016 . According to Figure 2, the majority of the work decreased in 2017, except the approach with ID8 (related with charging station planning and battery swap stations), which presents the largest number of publications for this year. Harb and Hamdan in [78] take into account that when new modern technology is introduced to the power grid, it should be compatible with the grid in order to improve its operation and ensure stability and reliability. In this work, several subjects are considered in which the EVs are involved with distribution networks, that is, assessment of different insertion levels of EVs in accordance with power quality (in terms of harmonic distortion) as well as voltage and frequency stability. In regards to power quality, the work shown in [79] focuses on experimental evaluation of EVs to reduce voltage unbalances by modulating the charging current according to local voltage measurements. This autonomous control could partially solve voltage quality issues without the need for grid upgrades or costly communication infrastructure, enabling a higher number of EVs to be integrated in the existing power network. The experiment is carried out with EVs that do not have the V2G technology incorporated but are able to modulate the charging current in steps according to the predefined droop control. Some energy market-oriented works, such as that shown in [80], proposes an eVoucher program to encourage participation of parking lots, with a high EV penetration rate, in the retail electricity market at distribution level.

As a vital part of smart grids, demand response supports the restoration of balance between electricity demand and supply. This concept is highlighted by [81], where a real-time charging scheme is proposed to coordinate the EV charging loads based on the dynamic electricity tariff. On the other hand, an optimization problem is formulated to maximize the number of EVs selected for charging at each time period. Two objective functions are in conflict: maximizing the EV owner's convenience in meeting all charging requests and minimizing the total electricity bill for the parking station. Similar contributions are presented in [82], focused on the real time interactions between energy supplier and the EVs users, in a fully distributed system in which the only information available to the end users is the current price. In this sense, a real-time charging pricing algorithm is introduced to maximize the aggregate utility of all the EV users and minimize the electricity cost generated by the energy supplier. In addition, the EV users and the energy supplier interact each other when running the distributed algorithm to find the optimal power consumption level, and the optimal price values to be revealed by the energy supplier, in order to adapt the users' demands constantly and maximize their own utility. Another study in [83] is presented in this context, defining demand 
response as "voluntary change of demand", proposing an approach to enable EV smart charging technology among residential customers. This proposal incorporates operation and analysis of power transactions between the energy user and the electricity grid, including the concept of power sharing among neighbors in the residential demand response framework. In the context of $V 2 G$, power system stability, and energy markets, the efforts done by [84] are highlighted. The introduction of network characteristics (distribution power losses and maximum power limits of the transformers and lines) in the V2G concept upgrades the accuracy of the EV model to participate in the load frequency control. This approach shows that EVs quickly respond during contingency and are very effective in driving the error to zero. From the other side, in [85] a multi-objective mathematical framework has been presented to cater frequency deviations at the grid level using a fleet of EVs. The objective functions of this model are presented below:

- minimization of grid frequency deviations using the available frequency regulation capacity, dealing with the trade-off between fulfilling EV energy demands and providing maximum grid support;

- maximization of V2G support to EVs while minimizing EV's battery degradation - the objective of this problem is to maximize the scheduling of EV participation while considering the trade-off with battery degradation issues;

- optimal regulation signal dispatch among aggregators and charging stations.

\subsection{Subperiod 2018}

Compared with 2017 and according to Figure 3, in 2018 the number of publications slightly increased, where EV demand management was the most addressed topic in this subperiod, followed by EVCS planning and studies associated with the V2G concept and ancillary services. In regard to EVCS profit, a parking lot management system (PLMS) is proposed in [86], which promotes EV recharging with the energy produced by a set of solar panels attached to the EVCS, instead of drawing energy from the grid. This behavior increases the parking lot owner's profit by selling more energy from the solar panels (avoiding high energy prices of the grid) and reduces the power network congestion in periods where the energy demand is relatively high. A similar approach is addressed by [87], which proposes an algorithm called JoAP (Joint Admission control and Pricing) to maximize the average profit of an EVCS. The profit is defined as the difference between the revenue and a penalty proportional to the average charging waiting time. This latter reflects the impatience of EV owners to wait in a queue for an excessively long time, which affects both the EVCS's reputation and the long-term profit. On the other side, the aggregators (entities that act as the mediators between the users and the utility operator) play an important role in the optimal regulation of the EV fleet charging plan, in order to minimize the overall cost of EV charging considering EV charging constraints. This aspect is widely dealt with by Mediwaththe and Smith in [88], providing a model for the competition among multiple EV aggregators by using a non-cooperative game-theoretic framework. Each aggregator determines the EV charging start time and charging energy profiles to minimize the EV charging energy cost, considering the actions taken by the neighboring EV aggregators. Other concepts have been recently adopted, such as the "internet of energy" addressed in [89], that refers to enhancing and automating the electricity infrastructure, e.g., EVCS, to move forward to a more efficient EV energy management. From the point of view of the EVCSs planning, several works are developed along this subperiod, considering the transportation and power networks. In [90], siting and sizing of fast charging stations is performed in coupled transportation and power grids with heterogeneous EV charging demands. The number of spots to be installed in a charging station is found in order to provide an adequate charging service quality measured by a performance metric. The transportation network is modeled by using a capacitated flow refueling location model, and Kirchhoff's laws are utilized to roughly approximate the electrical constraints of distribution networks. A similar focus is developed by [91] in terms of the EVCS location, by using a binary lightning search algorithm as an optimization technique for fast charging stations. Other works, such as those published in [92,93], 
have notable technical and economical contributions for EVCS planning. In [92], a two-level optimal planning approach is developed to optimize the siting, sizing, and demand drawn by the fast charging stations, and the number of chargers at each station is found, as part of a comprehensive benefit analysis. Furthermore, a more complex approach is performed in [93] from the cost-benefit analysis point of view. EVCS planning (siting and sizing) considers an economic analysis based on the life cycle cost and net present value, to provide optimal decisions for investors and charging stations operators. Given the probabilistic perspective, a two-stage stochastic programming model to determine the location and capacity of urban EVCSs is developed in [94], incorporating the uncertainties associated with the EV demand flows, charging patterns, arrival and departure times, and preferred walking distances. Due to the complexity of the two-stage stochastic problem, a heuristic is implemented for large-scale instances to obtain near optimal solutions. Novel strategies for EV charging are studied by $[95,96]$ with wireless charging systems, which allow the EV battery to charge remotely while moving over the highways. This technology mitigates the range limitation of EVs by using power tracks as additional sources of electric energy.

\subsection{Subperiod 2019}

Considering the rules in this paper to develop the power grids and EV-related research classification, it can be observed that the subperiod 2019 saw double the number of works in comparison with 2018 and has been, until now, the year with the largest number of publications, as depicted in Figure 3. According to the database in this research [6], in 2019 scenario studies were the most frequent, followed by works related to demand management, V2G concept, and power system stability. The fifth and sixth places are for EVCSs/BSSs and electricity markets, respectively, and the last two places are held by power quality and demand response research.

On the other hand, and with the purpose of providing a broader context for the current trends in terms of EV interactions with power grids, the IEA (International Energy Agency) published its annual report, the Global EV Outlook 2019 [97], which discusses key challenges in reference to implications of electric mobility for power systems. Particularly, the report emphasizes the potential of controlled EV charging to increase the flexibility in power systems via DSR (Demand-Side Response) services. This includes charging events during low-demand periods for shaping electricity demand, frequency response based on control signals, and supporting the increase of VRE (Variable Renewable Energy) generation in the power systems for reliability purposes. Likewise, the NARUC (National Association of Regulatory Utility Commissioners) reports in [98] the possibility of EVs as time-movable loads to increase the grid flexibility through rate design options, envisioned within the EVs participating in energy markets. This encompasses TOU (Time of Use) rates and dynamic RTP (Real Time Pricing) implementation for an efficient usage of existing assets, instead of implementing expensive upgrades in the distribution system to serve EVs. Similarly, the report performed by the Center on global Energy Policy in [99] highlights the relevance of demand response programs for aggregated EV charging, with pilot projects being developed in the states of California and Vermont. These projects are framed in assuring that EV charging times can respond to grid requests, and EV charging interruption can be triggered at super-peak times.

Considering the DSR context and EV participation in electricity markets, common ground for several works in the 2019 subperiod corresponds to the EV aggregator as a commercial middleman between the power grid operator and the EVs. The concept of EV aggregator is linked to facilitating EV interactions with power grids, in terms of reducing the charging cost, provision of ancillary services, and balancing between supply and demand [100], with a subsequent profit for both the aggregator and EV owners. Participation in day-ahead markets represents, in many cases, an instrument for the EV aggregator to get profit; furthermore, biding and pricing strategies should be considered due to the unpredictable nature of electricity markets [101]. Additionally, under incentive mechanisms an EV charging schedule adjustment is promoted according to the charging price adopted by the EV aggregator [102]. Therefore, improvement in the voltage profile and decrease in the power losses 
cost can be experimented by the power distribution operator, and customers are expected to make a profit [103]. Likewise, the EV aggregator coordinates charging and discharging strategies, taking into consideration EV driving patterns, features associated with the battery state of health [104], assessment of energy-efficient batteries [105], and unmodeled externalities acting on the energy price [106], with a direct effect on the aggregator's energy bids on the day-ahead market and its profitability [107]. On the other hand, sometimes the term "EV aggregator" is not used, and the DSR programs are directly performed by EV owners. In this sense, the DSR program can utilize a real-time pricing scheme, leading to a suitable option to alleviate network congestion when customers are encouraged to shift their charging process to off-peak periods. Compared with other price-based DSR programs, i.e., time of use, critical peak pricing, and peak time rebate, the real-time pricing scheme represents a more appropriate alternative for bill savings and dampening energy price volatility [108].

\subsection{Subperiod 2020: Recent Research}

During this subperiod, efforts around EV integration into the power grid have been adopted in terms of their spatial-temporal property [109]. This includes the introduction of traffic network as a remarkable component on the EV charging/discharging events. Additionally, for optimal and feasible operation, potential benefits of a dynamic distribution network reconfiguration have been considered, which complements V2G services and minimizes the total system cost [110]. A similar approach is taken in [111], showing the impact of traffic topological characteristics on EV charging. This results in practical applications such as EV load forecasting, construction of urban traffic networks, and charging and driving strategy optimization. On the other hand, and following the 2019 subperiod related with DSR programs, Bin Duan et al. in [112] propose an adjustment on electricity price via smart contracts between the user and the charging station, and Babar et al. in [113] present a mechanism for computing the EV charging prices using individualized energy consumption patterns of EVs contingent upon the region.

\section{Brief Observations}

As analyzed in the sections above, the paper database listed in [6] was divided into two ranges of time, the first set encompassed the elapsed time 1973-2015, and the second set of papers covered 2016-2019. This distribution resulted in a fair partition as each time range included almost half of the debugged database list. In this sense, a clear comparison between both divisions can be made, as presented in Figure 6.

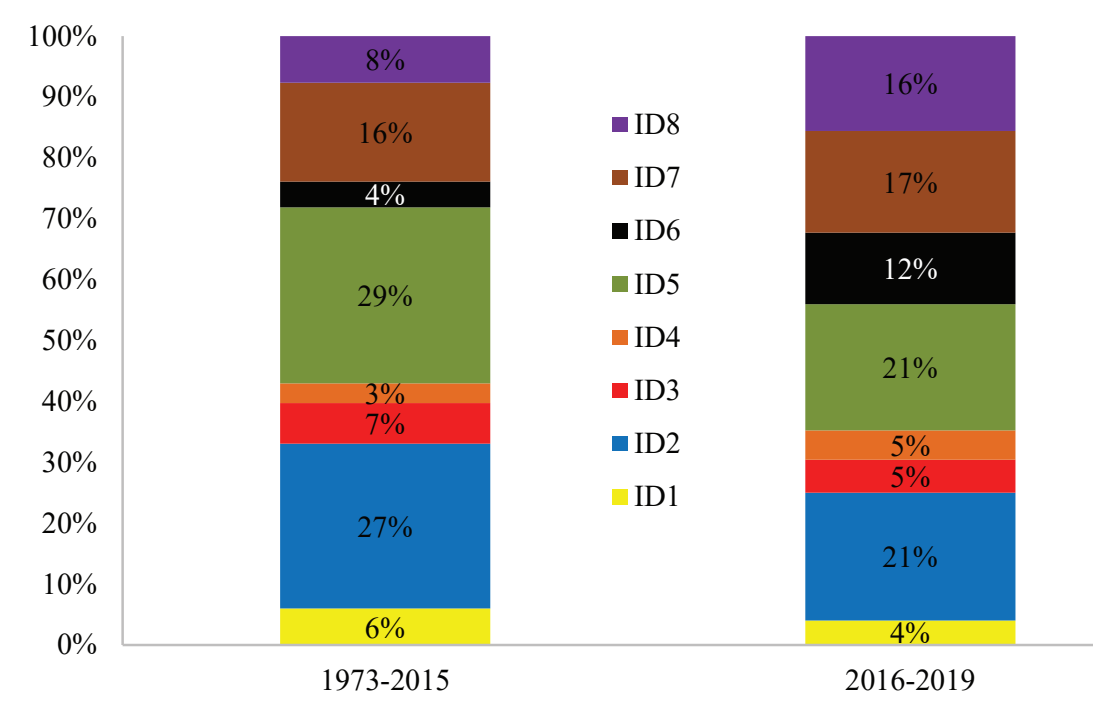

Figure 6. Comparison between the first and second half research periods. 
In regards with Figure 6, slight changes in the proportions of all categories can be noticed, except for the ID8 and ID6 corresponding to EVCSs and power system stability categories, respectively. An additional remark is framed within the time taken for both periods in finding almost the same number of works. An evident explanation comes from the fact that, in the second period (2016-2019), the subject of EVs and power grids was mature enough and developed, and many ideas had already been formed. Further, the first period (1973-2015), with a duration of 42 years, had to involve the evolution of the information dynamics and the first stages of research around interaction of EVs and power distribution systems.

\section{Conclusions and Future Works}

This paper presented a detailed review of the literature related to EVs and their impact on power distribution systems, considering categories that were carefully identified over an exhaustive examination on the IEEE Xplore database. The research encompassed the range of 1973 until the end of 2019, and 2008 was a starting point for increased publication.

Demand management has been identified as the category with a major presence throughout the development of this review. EV technologies are constantly growing, and researchers are always looking for methodologies to optimize several aspects in the EV charging process, i.e., energy drawn from the power grid and the time along the demand curve this process should take place. Moreover, other categories have been largely investigated, such as the Vehicle-to-Grid (V2G) topic and study of scenarios. The battery swap and charging stations topic, which involves the optimal location of these infrastructures throughout the power distribution system, has had notable relevance during the last few years as the spatial problem is solved, in contrast with several papers that only address the temporal and quantity aspects (e.g., when does the EV have to be recharged, and how much energy does the EV draw from the power grid?). The transportation network plays an important role in the optimal location of battery swap stations and EVCSs, despite the low number of publications in IEEE Xplore that also consider the transportation network.

It can be identified that the problems found in the subperiod 1973-1999, in regard to the impact of EVs on the distribution systems, i.e., inaccurate load model and non-desired demand peaks, are in conformity with the typical issues that EV charging may provide to the power grids in the coming years. For the sake of reliable power network operation, demand response programs shall be necessary to be implemented, as suggested by the IEA. On the other side, more research would be needed towards improving the EV load model, by exploration of data-driven EV load models instead of using the conventional ZIP model.

In regards with the classification performed in this review, some of the categories could be combined into one category. Since the V2G concept is the property of an EV to transfer energy to power network, other categories can be intrinsic within this topic, such as "power system stability" and "electricity markets". Furthermore, discrimination in several categories allows future researchers to directly find the corresponding sources of information for their purposes, knowingly that there is a meticulous process to select the papers listed in the database developed in this article.

According to the 2019 outlooks provided by prestigious governmental agencies such as IEA and USDRIVE, and different consultant organizations, the fields of demand management, demand response programs, and strategies for load profile shaving are more attractive rather than investing in expensive upgrades on power distribution infrastructure. Accordingly, it is proposed for future works to develop more specific literature reviews related to EVs and their corresponding involvement in demand response programs and electricity markets. Likewise, elaboration of an extended literature review encompassing the interaction between EVs and power grids can be considered, addressing other prominent databases such as ElSevier, Springer, MDPI, and Taylor and Francis. 


\section{Final Reflections}

Decarbonization of power systems has been a topic under discussion during the last decades due to the imminent depletion of oil reserves all over the world. One of the strategies to pursue this objective is framed within the electrification of transportation. Electric vehicles are considered as a promising alternative to reduce the dependence on fossil fuels and counteract the hibernation effect. On the other hand, the introduction of EVs in power distribution systems may undergo assets, i.e., transformers and conductors, to adverse effects and decrease the power grid performance. As demonstrated in the review in this paper, abundant research has been developed around EVs interaction with power grids, considering different trends that have emerged over the course of time as an effort to discriminate how EVs could be related with power grids. Not all the effects from EVs are dis-satisfactory for power distribution systems. As exhibited by many researchers, EVs may be able to provide ancillary services to power grids and increase its flexibility due to their nature of energy storage and movable loads. In this sense, improvement on load factor, frequency regulation, and support for penetration of renewable generation sources fall within the benefits of EVs on power distribution networks.

To this end, there should be a settled communication between the EVs and power grid operator, coordinated by an entity or an intermediate that in several works in this review has been called "the EV aggregator". This results in a more efficient exchange of information between the interested parties. As presented in AMI (Advanced Metering Infrastructure) system, different key hardware and software components have to be utilized by the aggregator in order to properly track and channel the abundant data coming from the EVs, i.e., charging and discharging profiles, driving patterns, demand response parameters, etc.

We assume that the EV aggregator will control the data exchange between the EVs and power grid utility, for demand response purposes or provision of network ancillary services, but this paradigm can be changed and, instead, the intermediate could be a figure of energy commercialization that negotiates the energy in wholesale or day-ahead market to sell it directly to EVs at consistent price. Furthermore, one can think about the existence of both figures, the "EV energy marketer" and "EV aggregator". The first one would negotiate energy for the EVs by using biding and pricing strategies, and the second one would be in charge of the technical segment. Under this context, the EV owner will have to choose a certain EV aggregator and/or "energy marketer" for operation and profitability purposes, as adopted nowadays with any household electric power installation.

Author Contributions: Conceptualization and writing-review and editing, A.A.-L., O.D.M., L.F.G.-N. All authors have read and agreed to the published version of the manuscript.

Funding: This project was financially supported by own funds of the authors.

Acknowledgments: The authors acknowledge the support provided by MINCIENCIAS, as manager of the Colombian National System of Science, Technology and Innovation (SNCTI).

Conflicts of Interest: The authors declare no conflicts of interest.

\section{References}

1. Arias, N.B.; Hashemi, S.; Andersen, P.B.; Træholt, C.; Romero, R. Distribution System Services Provided by Electric Vehicles: Recent Status, Challenges, and Future Prospects. IEEE Trans. Intell. Transp. Syst. 2019, 20, 4277-4296. [CrossRef]

2. Dubey, A.; Santoso, S. Electric vehicle charging on residential distribution systems: Impacts and mitigations. IEEE Access 2015, 3, 1871-1893. [CrossRef]

3. Deb, S.; Kalita, K.; Mahanta, P. Review of impact of electric vehicle charging station on the power grid. In Proceedings of the 2017 International Conference on Technological Advancements in Power and Energy (TAP Energy), Kollam, India, 21-23 December 2017; IEEE: Piscataway, NJ, USA, 2017; pp. 1-6. 
4. Jia, Q.S. On supply demand coordination in vehicle-to-grid-A brief literature review. In Proceedings of the 2018 33rd Youth Academic Annual Conference of Chinese Association of Automation (YAC), Nanjing, China, 18-20 May 2018; IEEE: Piscataway, NJ, USA, 2018; pp. 1083-1088.

5. Arias, A.; Martínez, L.H.; Hincapie, R.A.; Granada, M. An IEEE Xplore database literature review regarding the interaction between electric vehicles and power grids. In Proceedings of the 2015 IEEE PES Innovative Smart Grid Technologies Latin America (ISGT LATAM), Montevideo, Uruguay, 5-7 October 2015; IEEE: Piscataway, NJ, USA, 2015; pp. 673-678.

6. Papers Classification EVs-Power Grids 1973-2019. Available online: http:/ /academia.utp.edu.co/planeamiento/ sistemas-de-prueba/recarga-de-vehiculos-electricos-en-sistemas-de-distribucion-3/papers-classification-evspower-grids-1973-2019/ (accessed on May 2020).

7. Salihi, J.T. Energy requirements for electric cars and their impact on electric power generation and distribution systems. IEEE Trans. Ind. Appl. 1973, 5, 516-532. [CrossRef]

8. Patil, P. Prospects for electric vehicles. IEEE Aerosp. Electron. Syst. Mag. 1980, 5, 15-19. [CrossRef]

9. Heydt, G.T. The impact of electric vehicle deployment on load management straregies. IEEE Trans. Power Appar. Syst. 1983, 5, 1253-1259. [CrossRef]

10. Orr, J.A.; Emanuel, A.E.; Pileggi, D.J. Current harmonics, voltage distortion, and powers associated with electric vehicle battery chargers distributed on the residential power system. IEEE Trans. Ind. Appl. 1984, 4, 727-734. [CrossRef]

11. Rahman, S.; Shrestha, G. An investigation into the impact of electric vehicle load on the electric utility distribution system. IEEE Trans. Power Deliv. 1993, 8, 591-597. [CrossRef]

12. Suggs, C.R. Electric vehicles-driving the way to a cleaner future. In Conference Record Southcon; IEEE: Piscataway, NJ, USA, 1994; pp. 28-30.

13. KeKoster, D.; Morrow, K.P.; Schaub, D.A.; Hubele, N.F. Impact of electric vehicles on select air pollutants: A comprehensive model. IEEE Trans. Power Syst. 1995, 10, 1383-1388. [CrossRef]

14. Staats, P.; Grady, W.; Arapostathis, A.; Thallam, R. A statistical analysis of the effect of electric vehicle battery charging on distribution system harmonic voltages. IEEE Trans. Power Deliv. 1998, 13, 640-646. [CrossRef]

15. Chan, M.S.; Chau, K.; Chan, C. Modeling of electric vehicle chargers. In Proceedings of the 24th Annual Conference of the IECON'98 Industrial Electronics Society, Aachen, Germany, 31 August-4 September 1998; Volume 1, pp. 433-438.

16. Koyanagi, F.; Inuzuka, T.; Uriu, Y.; Yokoyama, R. Monte Carlo simulation on the demand impact by quick chargers for electric vehicles. In Proceedings of the Power Engineering Society Summer Meeting, Edmonton, AB, Canada, 18-22 July 1999; IEEE: Piscataway, NJ, USA, 1999; Volume 2, pp. 1031-1036.

17. Peres, L.P.; Lambert-Torres, G.; Nogueira, L.H. Electric vehicles impacts on daily load curves and environment. In Proceedings of the Electric Power Engineering, 1999. PowerTech Budapest 99. International Conference, Budapest, Hungary, 29 August-2 September 1999; IEEE: Piscataway, NJ, USA, 1999; p. 55.

18. Chan, C. The past, present and future of electric vehicle development. In Proceedings of the IEEE 1999 International Conference on Power Electronics and Drive Systems, Hong Kong, China, 27-29 July 1999; IEEE: Piscataway, NJ, USA, 1999; Volume 1, pp. 11-13.

19. Brahma, A.; Guezennec, Y.; Rizzoni, G. Optimal energy management in series hybrid electric vehicles. In Proceedings of the American Control Conference, Chicago, IL, USA, 28-30 June 2000; IEEE: Piscataway, NJ, USA, 2000; Volume 1, pp. 60-64.

20. Ceraolo, M.; Pede, G. Techniques for estimating the residual range of an electric vehicle. IEEE Trans. Veh. Technol. 2001, 50, 109-115. [CrossRef]

21. Gómez, J.C.; Morcos, M.M. Impact of EV battery chargers on the power quality of distribution systems. IEEE Trans. Power Deliv. 2003, 18, 975-981. [CrossRef]

22. Brooks, A. Integration of electric drive vehicles with the power grid-a new application for vehicle batteries. In Proceedings of the SeventeenthAnnual Battery Conference on Applications and Advances, Long Beach, CA, USA, 18 January 2002; IEEE: Piscataway, NJ, USA, 2002; p. 239.

23. De Breucker, S.; Jacqmaer, P.; De Brabandere, K.; Driesen, J.; Belmans, R. Grid power quality improvements using grid-coupled hybrid electric vehicles pemd 2006. In Proceedings of the 2006 3rd IET International Conference on Power Electronics, Machines and Drives-PEMD 2006, Dublin, Ireland, 4-6 April 2006. 
24. Das, T.; Aliprantis, D.C. Small-signal stability analysis of power system integrated with PHEVs. In Proceedings of the Energy 2030 Conference, ENERGY 2008, Atlanta, GA, USA, 17-18 November 2008; IEEE: Piscataway, NJ, USA, 2008; pp. 1-4.

25. Wang, L. Potential impacts of plug-in hybrid electric vehicles on locational marginal prices. In Proceedings of the Energy 2030 Conference, ENERGY 2008, Atlanta, GA, USA, 17-18 November 2008; IEEE: Piscataway, NJ, USA, 2008; pp. 1-7.

26. Guille, C.; Gross, G. Design of a conceptual framework for the V2G implementation. In Proceedings of the Energy 2030 Conference, ENERGY 2008, Atlanta, GA, USA, 17-18 November 2008; IEEE: Piscataway, NJ, USA, 2008; pp. 1-3.

27. Kramer, B.; Chakraborty, S.; Kroposki, B. A review of plug-in vehicles and vehicle-to-grid capability. In Proceedings of the Industrial Electronics, IECON 2008. 34th Annual Conference of IEEE, Orlando, FL, USA, 10-13 Novemer 2008; IEEE: Piscataway, NJ, USA, 2008; pp. 2278-2283.

28. Larsen, E.; Chandrashekhara, D.K.; Ostergard, J. Electric vehicles for improved operation of power systems with high wind power penetration, ENERGY 2008. In Proceedings of the Energy 2030 Conference, Atlanta, GA, USA, 17-18 November 2008; IEEE: Piscataway, NJ, USA, 2008; pp. 1-6.

29. Pina, A.; Ioakimidis, C.S.; Ferrao, P. Introduction of electric vehicles in an island as a driver to increase renewable energy penetration. In Proceedings of the Sustainable Energy Technologies, ICSET 2008. IEEE International Conference, Singapore, 24-27 November 2008; IEEE: Piscataway, NJ, USA, 2008; pp. 1108-1113.

30. Saber, A.Y.; Venayagamoorthy, G.K. Optimization of vehicle-to-grid scheduling in constrained parking lots. In Proceedings of the Power \& Energy Society General Meeting, Calgary, AB, Canada, 26-30 July 2009; IEEE: Piscataway, NJ, USA, 2009; pp. 1-8.

31. El Chehaly, M.; Saadeh, O.; Martinez, C.; Joos, G. Advantages and applications of vehicle to grid mode of operation in plug-in hybrid electric vehicles. In Proceedings of the Electrical Power \& Energy Conference (EPEC), Montreal, QC, Canada, 22-23 October 2009; IEEE: Piscataway, NJ, USA, 2009; pp. 1-6.

32. Lopes, J.P.; Soares, F.J.; Almeida, P.R. Identifying management procedures to deal with connection of electric vehicles in the grid. In Proceedings of the Powertech, Bucharest, Romania, 28 June-2 July 2009; IEEE: Piscataway, NJ, USA, 2009; pp. 1-8.

33. Clement, K.; Haesen, E.; Driesen, J. Coordinated charging of multiple plug-in hybrid electric vehicles in residential distribution grids. In Proceedings of the Power Systems Conference and Exposition, PSCE'09. IEEE/PES, Seattle, WA, USA, 15-18 March 2009; Piscataway, NJ, USA, 2009; pp. 1-7.

34. Acha, S.; Green, T.C.; Shah, N. Impacts of plug-in hybrid vehicles and combined heat and power technologies on electric and gas distribution network losses. In Proceedings of the Sustainable Alternative Energy (SAE), 2009 PES/IAS Conference, Valencia, Spain, 28 September 2009; IEEE: Piscataway, NJ, USA, 2009; pp. 1-7.

35. Wang, Z.; Liu, P. Analysis on storage power of electric vehicle charging station. In Proceedings of the Power and Energy Engineering Conference (APPEEC), 2010 Asia-Pacific, Chengdu, China, 28-31 March 2010; IEEE: Piscataway, NJ, USA, 2010; pp. 1-4.

36. Singh, M.; Kumar, P.; Kar, I. Analysis of vehicle to grid concept in Indian scenario. In Proceedings of the Power Electronics and Motion Control Conference (EPE/PEMC), 2010 14th International, Ohrid, North Macedonia, 6-8 September 2010; IEEE: Piscataway, NJ, USA, 2010.

37. Acha, S.; Green, T.C.; Shah, N. Effects of optimised plug-in hybrid vehicle charging strategies on electric distribution network losses. In Proceedings of the Transmission and Distribution Conference and Exposition, 2010 IEEE PES, New Orleans, LA, USA, 19-22 April 2010; IEEE: Piscataway, NJ, USA, 2010; pp. 1-6.

38. Devie, A.; Montaru, M.; Pelissier, S.; Venet, P. Classification of duty pulses affecting energy storage systems in vehicular applications. In Proceedings of the 2010 IEEE Vehicle Power and Propulsion Conference, Lille, France, 1-3 September 2010; IEEE: Piscataway, NJ, USA, 2010; pp. 1-6.

39. Mallette, M.; Venkataramanan, G. Financial incentives to encourage demand response participation by plug-in hybrid electric vehicle owners. In Proceedings of the Energy Conversion Congress andExposition (ECCE), 2010, Atlanta, GA, USA, 12-16 September 2010; IEEE: Piscataway, NJ, USA, 2010; pp. 4278-4284.

40. Makasa, K.J.; Venayagamoorthy, G.K. Estimation of voltage stability index in a power system with Plug-in Electric Vehicles. In Proceedings of the Bulk Power System Dynamics and Control (iREP)-VIII (iREP), 2010 iREP Symposium, Rio de Janeiro, Brazil, 1-6 August 2010; IEEE: Piscataway, NJ, USA, 2010; pp. 1-7. 
41. Fluhr, J.; Ahlert, K.H.; Weinhardt, C. A stochastic model for simulating the availability of electric vehicles for services to the power grid. In Proceedings of the System Sciences (HICSS), 2010 43rd Hawaii International Conference, Honolulu, HI, USA, 5-8 January 2010; IEEE: Piscataway, NJ, USA, 2010; pp. 1-10.

42. Soares, F.; Lopes, J.P.; Almeida, P.R. A Monte Carlo method to evaluate electric vehicles impacts in distribution networks. In Proceedings of the Innovative Technologies for an Efficient and Reliable Electricity Supply (CITRES), 2010 IEEE Conference, Waltham, MA, USA, 27-29 September 2010; IEEE: Piscataway, NJ, USA, 2010; pp. 365-372.

43. Yamashita, D.; Niimura, T.; Takamori, H.; Yokoyama, R. A dynamic model of plug-in electric vehicle markets and charging infrastructure for the evaluation of effects of policy initiatives. In Proceedings of the Power Systems Conference and Exposition (PSCE), 2011 IEEE/PES, Phoenix, AZ, USA, 20-23 March 2011; IEEE: Piscataway, NJ, USA, 2011; pp. 1-8.

44. Almeida, P.R.; Lopes, J.P.; Soares, F.; Seca, L. Electric vehicles participating in frequency control: Operating islanded systems with large penetration of renewable power sources. In Proceedings of the PowerTech, 2011 IEEE Trondheim, Trondheim, Norway, 19-23 June 2011; IEEE: Piscataway, NJ, USA, 2011; pp. 1-6.

45. Wang, X.; Tian, W.; He, J.; Huang, M.; Jiang, J.; Han, H. The application of electric vehicles as mobile distributed energy storage units in smart grid. In Proceedings of the Power and Energy Engineering Conference (APPEEC), 2011 Asia-Pacific, Wuhan, China, 25-28 March 2011; IEEE: Piscataway, NJ, USA, 2011; pp. 1-5.

46. Kezunovic, M. BEVs/PHEVs as dispersed energy storage in smart grid. In Proceedings of the Innovative Smart Grid Technologies (ISGT), 2012 IEEEPES, Washington, DC, USA, 16-20 January 2012; IEEE: Piscataway, NJ, USA, 2012; pp. 1-2.

47. Feng, L.; Ge, S.; Liu, H. Electric vehicle charging station planning based on weighted voronoi diagram. In Proceedings of the Power and Energy Engineering Conference (APPEEC), 2012 Asia-Pacific, Changchun, China, 16-18 December 2011; IEEE: Piscataway, NJ, USA, 2011; pp. 1-5.

48. Falahati, B.; Fu, Y.; Darabi, Z.; Wu, L. Reliability assessment of power systems considering the large-scale PHEV integration. In Proceedings of the Vehicle Power and Propulsion Conference (VPPC), Chicago, IL, USA, 6-9 September 2011; IEEE: Piscataway, NJ, USA, 2011; pp. 1-6.

49. Rolink, J.; Rehtanz, C. Capacity of low voltage grids for electric vehicles. In Proceedings of the Environment and Electrical Engineering (EEEIC), 2011 10th International Conference, Rome, Italy, 8-11 May 2011; IEEE: Piscataway, NJ, USA, 2011; pp. 1-4.

50. Grahn, P.; Söder, L. The customer perspective of the electric vehicles role on the electricity market. In Proceedings of the Energy Market (EEM), 2011 8th International Conference on the European, Zagreb, Croatia, 25-27 May 2011; IEEE: Piscataway, NJ, USA, 2011; pp. 141-148.

51. Turker, H.; Hably, A.; Bacha, S. Dynamic programming for optimal integration of plug-in hybrid electric vehicles (phevs) in residential electric grid areas. In Proceedings of the IECON 2012-38th Annual Conference on IEEE Industrial Electronics Society, Montreal, QC, Canada, 25-28 October 2012; IEEE: Piscataway, NJ, USA, 2012; pp. 2942-2948.

52. O'Connell, N.; Wu, Q.; Stergaard, J. Efficient determination of distribution tariffs for the prevention of congestion from ev charging. In Proceedings of the Power and Energy Society General Meeting, San Diego, CA, USA, 22-26 July 2012; IEEE: Piscataway, NJ, USA, 2012; pp. 1-8.

53. Zheng, D.; Wen, F.; Huang, J. Optimal planning of battery swap stations. In Proceedings of the International Conference On Sustainable Power Generation And Supply, Hangzhou, China, 8-9 September 2012.

54. Kutt, L.; Saarijárvi, E.; Lehtonen, M.; Mõlder, H.; Niitsoo, J. A review of the harmonic and unbalance effects in electrical distribution networks due to EV charging. In Proceedings of the Environment and Electrical Engineering (EEEIC), 2013 12th International Conference, Wroclaw, Poland, 5-8 May 2013; IEEE: Piscataway, NJ, USA, 2013; pp. 556-561.

55. Kutt, L.; Saarijarvi, E.; Lehtonen, M.; Molder, H.; Niitsoo, J. Current harmonics of EV chargers and effects of diversity to charging load current distortions in distribution networks. In Proceedings of the Connected Vehicles and Expo (ICCVE), 2013 International Conference, Las Vegas, NV, USA, 2-6 December 2013; IEEE: Piscataway, NJ, USA, 2013; pp. 726-731.

56. Tuttle, D.P.; Fares, R.L.; Baldick, R.; Webber, M.E. Plug-In Vehicle to Home (V2H) duration and power output capability. In Proceedings of the Transportation Electrification Conference and Expo (ITEC), Detroit, MI, USA, 16-19 June 2013; IEEE: Piscataway, NJ, USA, 2013; pp. 1-7. 
57. Andrés, A.L.; Geovanny, M.G.; Camila, P.G.; Hincapié, R.A.; Mauricio, G.E. Optimal charging schedule of electric vehicles considering variation of energy price. In Proceedings of the Transmission \& Distribution Conference and Exposition-Latin America (PES T\&D-LA), 2014 IEEE PES, Medellin, Colombia, 10-13 September 2014; IEEE: Piscataway, NJ, USA, 2014; pp. 1-5.

58. Su, J.; Marmaras, C.E.; Xydas, E.S. Technical and environmental impact of electric vehicles in distribution networks. In Proceedings of the Green Energy for Sustainable Development (ICUE), 2014 International Conference and Utility Exhibition, Pattaya, Thailand, 19-21 March 2014; IEEE: Piscataway, NJ, USA, 2014; pp. 1-9.

59. Zheng, Y.; Dong, Z.Y.; Xu, Y.; Meng, K.; Zhao, J.H.; Qiu, J. Electric vehicle battery charging/swap stations in distribution systems: Comparison study and optimal planning. IEEE Trans. Power Syst. 2014, 29, 221-229. [CrossRef]

60. Xu, N.; Chung, C. Reliability evaluation of distribution systems including vehicle-to-home and vehicle-to-grid. IEEE Trans. Power Syst. 2016, 31, 759-768. [CrossRef]

61. Riviere, E.; Venet, P.; Sari, A.; Meniere, F.; Bultel, Y. LiFePO4 battery state of health online estimation using electric vehicle embedded incremental capacity analysis. In Proceedings of the 2015 IEEE Vehicle Power and Propulsion Conference (VPPC), Montreal, QC, Canada, 19-22 October 2015; IEEE: Piscataway, NJ, USA, 2015; pp. 1-6.

62. Illing, B.; Warweg, O. Analysis of international approaches to integrate electric vehicles into energy market. In Proceedings of the European Energy Market (EEM), 2015 12th International Conference, Lisbon, Portugal, 19-22 May 2015; IEEE: Piscataway, NJ, USA, 2015; pp. 1-5.

63. Vagropoulos, S.I.; Kyriazidis, D.K.; Bakirtzis, A.G. Real-time charging management framework for electric vehicle aggregators in a market environment. IEEE Trans. Smart Grid 2016, 7, 948-957. [CrossRef]

64. Gough, B.; Rowley, P.; Khan, S.; Walsh, C. The value of electric vehicles in the context of evolving electricity markets. In Proceedings of the European Energy Market (EEM), 2015 12th International Conference, Lisbon, Portugal, 19-22 May 2015; IEEE: Piscataway, NJ, USA, 2015; pp. 1-6.

65. González-Romera, E.; Barrero-González, F.; Romero-Cadaval, E.; Milanés-Montero, M.I. Overview of plug-in electric vehicles as providers of ancillary services. In Proceedings of the Compatibility and Power Electronics (CPE), 2015 9th International Conference, Costa da Caparica, Portugal, 24-26 June 2015; IEEE: Piscataway, NJ, USA, 2015; pp. 516-521.

66. Izadkhast, S.; Garcia-Gonzalez, P.; Frías, P. An aggregate model of plug-in electric vehicles for primary frequency control. IEEE Trans. Power Syst. 2015, 30, 1475-1482. [CrossRef]

67. Bayat, M.; Sheshyekani, K.; Rezazadeh, A. A unified framework for participation of responsive end-user devices in voltage and frequency control of the smart grid. IEEE Trans. Power Syst. 2015, 30, 1369-1379. [CrossRef]

68. Hussain, M.N.; Agarwal, V. A new control technique to enhance the stability of a DC microgrid and to reduce battery current ripple during the charging of plug-in electric vehicles. In Proceedings of the Environment and Electrical Engineering (EEEIC), 2015 IEEE 15th International Conference, Rome, Italy, 10-13 June 2015; IEEE: Piscataway, NJ, USA, 2015; pp. 2189-2193.

69. Poornazaryan, B.; Abedi, M.; Gharehpetian, G.; Karimyan, P. Application of PHEVs in controlling voltage and frequency of autonomous microgrids. In Proceedings of the Power System Conference (PSC), 2015 30th International, Tehran, Iran, 23-25 November 2015; IEEE: Piscataway, NJ, USA, 2015; pp. 60-66.

70. Arias, A.; Martínez, L.H.; Hincapie, R.A.; Granada, M. An efficient approach to solve the combination between Battery Swap Station Location and CVRP by using the MTZ formulation. In Proceedings of the Innovative Smart Grid Technologies Latin America (ISGT LATAM), 2015 IEEE PES, Montevideo, Uruguay, 5-7 October 2015; IEEE: Piscataway, NJ, USA, 2015; pp. 574-578.

71. Zhang, B.; Kezunovic, M. Impact on power system flexibility by electric vehicle participation in ramp market. IEEE Trans. Smart Grid 2016, 7, 1285-1294. [CrossRef]

72. Sarker, M.R.; Dvorkin, Y.; Ortega-Vazquez, M.A. Optimal participation of an electric vehicle aggregator in day-ahead energy and reserve markets. IEEE Trans. Power Syst. 2016, 31, 3506-3515. [CrossRef]

73. Johal, R.; Jain, D. Demand response as a load shaping tool integrating electric vehicles. In Proceedings of the Power Systems (ICPS), 2016 IEEE 6th International Conference, New Delhi, India, 4-6 March 2016; IEEE: Piscataway, NJ, USA, 2016; pp. 1-6. 
74. Hafez, O.; Bhattacharya, K. Integrating ev charging stations as smart loads for demand response provisions in distribution systems. IEEE Trans. Smart Grid 2016, 9, 1096-1106

75. Behboodi, S.; Crawford, C.; Djilali, N.; Chassin, D.P. Integration of price-driven demand response using plug-in electric vehicles in smart grids. In Proceedings of the Electrical and Computer Engineering (CCECE), 2016 IEEE Canadian Conference, Vancouver, BC, Canada, 15-18 May 2016; IEEE: Piscataway, NJ, USA, 2016; pp. 1-5.

76. Catalão, J.; Osorio, G.; Gil, F.; Aghaei, J.; Barani, M.; Heydarian Forushani, E. Optimal Behavior of Electric Vehicle Parking Lots as Demand Response Aggregation Agents. 2016. IEEE Trans. Smart Grid 2016, 7, 2654-2665

77. Cross, J.; Hartshorn, R. My Electric Avenue: Integrating Electric Vehicles into the Electrical Networks. In Proceedings of the 6th Hybrid and Electric Vehicles Conference (HEVC 2016), London, UK, 2-3 November 2016.

78. Harb, A.; Hamdan, M. Power quality and stability impacts of Vehicle to grid (V2G) connection. In Proceedings of the Renewable Energy Congress (IREC), 2017 8th International, Amman, Jordan, 21-23 March 2017; IEEE: Piscataway, NJ, USA, 2017; pp. 1-6.

79. Martinenas, S.; Knezović, K.; Marinelli, M. Management of power quality issues in low voltage networks using electric vehicles: Experimental validation. IEEE Trans. Power Deliv. 2017, 32, 971-979. [CrossRef]

80. Chen, T.; Pourbabak, H.; Liang, Z.; Su, W.; Yu, P. Participation of electric vehicle parking lots into retail electricity market with evoucher mechanism. In Proceedings of the Transportation Electrification Asia-Pacific (ITEC Asia-Pacific), 2017 IEEE Conference and Exp, Harbin, China, 7-10 August 2017; IEEE: Piscataway, NJ, USA, 2017; pp. 1-5.

81. Yao, L.; Lim, W.H.; Tsai, T.S. A real-time charging scheme for demand response in electric vehicle parking station. IEEE Trans. Smart Grid 2017, 8, 52-62. [CrossRef]

82. Lu, Z.; Qi, J.; Zhang, J.; He, L.; Zhao, H. Modelling dynamic demand response for plug-in hybrid electric vehicles based on real-time charging pricing. Iet Gener. Transm. Distrib. 2017, 11, 228-235. [CrossRef]

83. Pal, S.; Kumar, R. Electric Vehicle Scheduling Strategy in Residential Demand Response Programs with Neighbor Connection. IEEE Trans. Ind. Informatics 2017. 14, 980-988. [CrossRef]

84. Dutta, A.; Debbarma, S. Frequency Regulation in Deregulated Market Using Vehicle-to-Grid Services in Residential Distribution Network. IEEE Syst. J. 2017. 12, 2812-2820. [CrossRef]

85. Kaur, K.; Singh, M.; Kumar, N. Multiobjective Optimization for Frequency Support Using Electric Vehicles: An Aggregator-Based Hierarchical Control Mechanism. IEEE Syst. J. 2017. 13, 771-782. [CrossRef]

86. Mathur, A.K.; Yemula, P.K. Optimal Charging Schedule for Electric Vehicles in Parking Lot with Solar Power Generation. In Proceedings of the 2018 IEEE Innovative Smart Grid Technologies-Asia (ISGT Asia), Singapore, 22-25 May 2018; IEEE: Piscataway, NJ, USA, 2018; pp. 611-615.

87. Wang, S.; Bi, S.; Zhang, Y.J.; Huang, J. Electrical Vehicle Charging Station Profit Maximization: Admission, Pricing, and Online Scheduling. IEEE Trans. Sustain. Energy 2018, 9, 1722-1731. [CrossRef]

88. Mediwaththe, C.P.; Smith, D.B. Game-Theoretic Electric Vehicle Charging Management Resilient to Non-Ideal User Behavior. IEEE Trans. Intell. Transp. Syst. 2018, 19, 3486-3495. [CrossRef]

89. Lin, C.C.; Deng, D.J.; Kuo, C.C.; Liang, Y.L. Optimal charging control of energy storage and electric vehicle of an individual in the internet of energy with energy trading. IEEE Trans. Ind. Inform. 2018, 14, 2570-2578. [CrossRef]

90. Zhang, H.; Moura, S.J.; Hu, Z.; Qi, W.; Song, Y. A Second-Order Cone Programming Model for Planning PEV Fast-Charging Stations. IEEE Trans. Power Syst. 2018, 33, 2763-2777. [CrossRef]

91. Islam, M.M.; Shareef, H.; Mohamed, A. Optimal location and sizing of fast charging stations for electric vehicles by incorporating traffic and power networks. Iet Intell. Transp. Syst. 2018, 12, 947-957. [CrossRef]

92. Sun, S.; Yang, Q.; Wenjung, Y. A hierarchical optimal planning approach for plug-in electric vehicle fast charging stations based on temporal-SoC charging demand characterization. Iet Gener. Transm. Distrib. 2018. 12, 4388-4395. [CrossRef]

93. Huang, X.; Chen, J.; Yang, H.; Cao, Y.; Guan, W.; Huang, B. Economic planning approach for electric vehicle charging stations integrating traffic and power grid constraints. Iet Gener. Transm. Distrib. 2018, 12, 3925-3934. [CrossRef]

94. Faridimehr, S.; Venkatachalam, S.; Chinnam, R.B. A stochastic programming approach for electric vehicle charging network design. IEEE Trans. Intell. Transp. Syst. 2018, 20, 1870-1882. [CrossRef]

95. Li, C.; Ding, T.; Liu, X.; Huang, C. An Electric Vehicle Routing Optimization Model with Hybrid Plug-in and Wireless Charging Systems. IEEE Access 2018, 6, 27569-27578. [CrossRef] 
96. Hwang, I.; Jang, Y.J.; Ko, Y.D.; Lee, M.S. System optimization for dynamic wireless charging electric vehicles operating in a multiple-route environment. IEEE Trans. Intell. Transp. Syst. 2018, 19, 1709-1726. [CrossRef]

97. Outlook, I.G.E. Scaling-Up the Transition to Electric Mobility; IEA: Paris, France, 2019.

98. Harper, C.; Gregory McAndrews, D.S.B. Electric Vehicles: Key Trends, Issues, and Considerations for State Regulators. In Proceedings of the Technical Report; National Association of Regulatory Utility Commissioners NARUC: Washington, DC, USA, 2019.

99. Hove, A.; Sandalow, D. Electric Vehicle Charging in China and the United States. Columbia, School of International and Public Affairs, Center on Global Energy Policy. Available online: https: / / energypolicy. columbia.edu/sites/default/files/file-uploads/EV_ChargingChina-CGEP_Report_Final.pdf (accessed on 22 December 2019).

100. Doumen, S.; Paterakis, N.G. Economic viability of smart charging EVs in the Dutch ancillary service markets. In Proceedings of the 2019 International Conference on Smart Energy Systems and Technologies (SEST), Porto, Portugal, 9-11 September 2019; IEEE: Piscataway, NJ, USA, 2019; pp. 1-6.

101. Han, B.; Lu, S.; Xue, F.; Jiang, L. Day-ahead electric vehicle aggregator bidding strategy using stochastic programming in an uncertain reserve market. Iet Gener. Transm. Distrib. 2019, 13, 2517-2525. [CrossRef]

102. Jiang, Z.; Ai, Q.; Hao, R.; Yousif, M.; Zhang, Y. Joint Optimization for Bidding and Pricing of Electric Vehicle Aggregators Considering Reserve Provision and EV Response. In Proceedings of the 2019 IEEE Power \& Energy Society General Meeting (PESGM), Atlanta, GA, USA, 4-8 August 2019; IEEE: Piscataway, NJ, USA, 2019; pp. 1-5.

103. Hashemi, B.; Shahabi, M.; Teimourzadeh-Baboli, P. Stochastic-based optimal charging strategy for plug-in electric vehicles aggregator under incentive and regulatory policies of DSO. IEEE Trans. Veh. Technol. 2019, 68, 3234-3245. [CrossRef]

104. Ren, H.; Zhang, A.; Li, W. Study on Optimal V2G Pricing Strategy under Multi-Aggregator Competition Based on Game Theory. In Proceedings of the 2019 IEEE Sustainable Power and Energy Conference (iSPEC), Beijing, China, 21-23 November 2019; IEEE: Piscataway, NJ, USA, 2019; pp. 1027-1032.

105. Redondo-Iglesias, E.; Venet, P.; Pelissier, S. Efficiency degradation model of lithium-ion batteries for electric vehicles. IEEE Trans. Ind. Appl. 2018, 55, 1932-1940. [CrossRef]

106. Fele, F; Margellos, K. Scenario-based Robust Scheduling for Electric Vehicle Charging Games. In Proceedings of the 2019 IEEE International Conference on Environment and Electrical Engineering and 2019 IEEE Industrial and Commercial Power Systems Europe (EEEIC/I\&CPS Europe), Genova, Italy, 11-14 June 2019; IEEE: Piscataway, NJ, USA, 2019; pp. 1-6.

107. Gomes, I.; Melicio, R.; Mendes, V. Stochastic Management of Bidirectional Electric Vehicles: The Case of an Electric Vehicles Aggregator. In Proceedings of the 2019 IEEE International Conference on Environment and Electrical Engineering and 2019 IEEE Industrial and Commercial Power Systems Europe (EEEIC/I\&CPS Europe), Genova, Italy, 11-14 June 2019; IEEE: Piscataway, NJ, USA, 2019; pp. 1-5.

108. Skolthanarat, S.; Somsiri, P.; Tungpimolrut, K. Contribution of Real-Time Pricing to Impacts of Electric Cars on Distribution Network. In Proceedings of the 2019 IEEE Industry Applications Society Annual Meeting, Baltimore, MD, USA, 29 September-3 October 2019; IEEE: Piscataway, NJ, USA, 2019; pp. 1-5.

109. Chen, C.; Chen, J.; Wang, Y.; Duan, S.; Cai, T.; Jia, S. A Price Optimization Method for Microgrid Economic Operation Considering Across-Time-and-Space Energy Transmission of Electric Vehicles. IEEE Trans. Ind. Inform. 2019, 16, 1873-1884

110. Guo, Z.; Zhou, Z.; Zhou, Y. Impacts of Integrating Topology Reconfiguration and Vehicle-to-Grid Technologies on Distribution System Operation. IEEE Trans. Sustain. Energy 2019. 11, 1023-1032

111. Chen, C.; Wu, Z.; Zhang, Y. The Charging Characteristics of Large-Scale Electric Vehicle Group Considering Characteristics of Traffic Network. IEEE Access 2020, 8, 32542-32550. [CrossRef]

112. Duan, B.; Xin, K.; Zhong, Y. Optimal Dispatching of Electric Vehicles Based on Smart Contract and Internet of Things. IEEE Access 2019, 8, 9630-9639. [CrossRef]

113. Rasheed, M.B.; Awais, M.; Alquthami, T.; Khan, I. An Optimal Scheduling and Distributed Pricing Mechanism for Multi-Region Electric Vehicle Charging in Smart Grid. IEEE Access 2020, 8, 40298-40312. [CrossRef]

(C) 2020 by the authors. Licensee MDPI, Basel, Switzerland. This article is an open access article distributed under the terms and conditions of the Creative Commons Attribution (CC BY) license (http:/ / creativecommons.org/licenses/by/4.0/). 